\title{
Genetic Variability for Yield and Yield Contributing Traits of Rice under Aerobic Condition in Assam, India
}

\author{
Hrishikesh Ojah $^{1 *}$, P. Talukdar ${ }^{2}$, D. Sarma ${ }^{2}$ and Rumjhum Goswami ${ }^{2}$ \\ ${ }^{1}$ SCS College of Agriculture, AAU, Dhubri-783376 \\ ${ }^{2}$ Department of $P B G, A A U$, Jorhat-13, India \\ *Corresponding author
}

\section{Keywords}

Aerobic rice, Genetic variability, Heritability, G x E interaction and Genetic advance

Article Info

Accepted:

12 June 2019

Available Online:

10 July 2019

\section{A B S T R A C T}

An investigation had been taken up to assess few rice genotypes for their inclusion in breeding programme to develop varieties suitable for aerobic cultivation. The experiment was carried out at the experimental field of Sarat Chandra Sinha College of Agriculture, Assam Agricultural University, Dhubri. Evaluation of fifteen rice genotypes, comprising ten traditional cultivars and five high yielding varieties both in aerobic and irrigated lowland situations revealed sufficient variability and interaction of the genotypes with the environment. Pooled analysis of variance revealed significance of $\mathrm{G} \times \mathrm{E}$ interaction in the expression of most of the characters. Expression of all the traits except panicle harvest index, 100 grain weight and root shoot ratio were significantly differed in both the environments. For most of the characters, mean values were estimated to be higher under irrigated lowland condition, whereas, the ranges of the characters were found to be higher under aerobic condition. The magnitude of difference between correspondence phenotypic coefficient of variance (PCV) and genotypic coefficient of variance (GCV) were lower in aerobic condition, coupled with relatively higher estimates of heritability and genetic advance. Proline content, height growth rate, shoot weight, grain yield and plant height exhibited high heritability with high genetic advance as percent of mean hence, these characters showed promise in bringing genetic improvement under selection in aerobic condition.

\section{Introduction}

Rice, the staple food for nearly $65 \%$ of Indian population is being cultivated primarily in low land situation which consumes almost half of the water utilized for agricultural production. The depleting water resource demands some alternative production techniques without compromising the productivity. Among various such approaches, aerobic cultivation of rice is one of the most promising options.

Aerobic rice system is an approach to reduce water inputs in rice by growing the crop aerobically like an irrigated upland crop such as wheat and maize. Early experiments on aerobic rice revealed that water input in aerobic rice was 50 per cent lower (only 470$650 \mathrm{~mm}$ ) and water productivity was higher 
by $64-88$ per cent than the irrigated lowland rice (Bouman et al., 2002). Aerobic rice is targeted to water-short areas where there is irrigation but where the water supply is insufficient for growing lowland rice and to rainfed areas where rainfall is sufficient to frequently bring the soil water content close to field capacity.

A key component of success in aerobic rice system is selection of appropriate cultivars. Aerobic rice varieties are designed to be high yielding, input responsive, and weed competitive to attain high yields under aerobic soil conditions. They are better adapted to intensified management with moderate input use than traditional upland rice, which has low harvest index (HI) and is prone to lodging when fertilized (Atlin et al., 2006). Aerobic rice also has a high degree of drought tolerance to cope with periods of water stress that occur in rainfed production. Such genotypes can be developed by crossing upland-adapted, weed-competitive, and drought tolerant donors (usually traditional upland rice varieties) to high-yielding, inputresponsive lowland varieties (usually modern lowland varieties developed for irrigated production systems), employing appropriate breeding strategies.

Success of this approach is largely dependent on availability of suitable location specific high yielding cultivars combing certain traits found in germplasm adapted to the irrigated environment with other traits found in upland germplasm. A thorough knowledge on nature and magnitude of genetic variability, heritability, genetic advance etc are prerequisite of launching any breeding programme. The broad aim of the present investigation was to study some adaptive traits under aerobic cultivation in few potential genotypes, knowledge of which are to be utilized for designing any future breeding programme intended to bringing about genetic improvement in aerobic rice.

\section{Materials and Methods}

The experimental material for the present study comprised of ten traditional cultivars (both exotic and indigenous) with putative drought tolerance ability and five high yielding modern cultivars (Table 1). All the genotypes were grown in randomized block design with 3 replications both under aerobic and irrigated lowland conditions in the summer or ahu season of 2015. Each genotype was grown in $3 \mathrm{~m} \times 3 \mathrm{~m}$ plot with $20 \times 15 \mathrm{~cm}$ spacing in the Instructional cum Research Farm, Sarat Chandra Sinha College of Agriculture, Assam Agricultural University, Dhubri, Assam, India, Standard agronomic practices and plant protection measures were followed.

Data were recorded on 5 randomly sampled plants from each entry in each replication for the following traits: Plant height $(\mathrm{PH})$, Height growth rates (HGR), Number of productive tillers (PT), Days to anthesis (DA), Days to maturity (DM), Harvest index (HI), Spikelet fertility (SF), Grain yield per plant (GY), Panicle harvest index (PHI), 100 grain weight (HGW), Relative water content (RWC), Root dry weight (RW), Shoot dry weight (SW), Root shoot ratio (RSR), Root volume (RV), Proline content (Pro.) and Chlorophyll content (Chl.)

Data were subjected to individual ANOVA and pooled ANOVA for presence of variability in the genotypes. Further, genetic parameters like Genotypic coefficient of variation $(\mathrm{GCV})$, phenotypic coefficient of variation (PCV), heritability in broad sense and genetic advance as percent of mean were worked out following appropriate statistical procedure.

\section{Results and Discussion}

Analysis of variance for yield and adaptive characters indicated significant differences 
among the genotypes in both the environments. Patel et al., (2014), Nilanjaya et al., (2015) also observed sufficient variability among the genotypes.

Pooled analysis of variance revealed that expression of all the traits except panicle harvest index, 100 grain weight and root shoot ratio were significantly differed in both the environments. Similarly interaction of genotypes with environment created significant variation in most of the characters except days to anthesis, days to maturity, plant height, height growth rate, 100 grain weight, harvest index, chlorophyll content and shoot weight. This finding supported the need to assess the parents both in aerobic and irrigated conditions in order to derive precise information of their performance. This implied the possibility of exploiting these genotypes in studying the inheritance of the traits and also their inclusion in breeding programmes for achieving further improvement (Table 2 and 3 ).
A perusal of mean data over both the environments revealed that slightly higher grain yield was realized under aerobic environment. For most of the characters, mean values were estimated to be higher under irrigated lowland condition, whereas, the ranges of the characters were found to be higher under aerobic condition. This indicated that, although the performance under irrigated lowland situation was higher but the genotypes responded less uniformly under aerobic condition. However grain yield along with number of productive tillers per plant, days to anthesis, days to maturity and root volume were found to be higher under aerobic condition. All the root traits along with 100 grain weight and chlorophyll content revealed higher estimate of range under irrigated lowland condition. Highest grain weight was recorded for Gopinath (34.5 g) and Sahabhagi $(28.2 \mathrm{~g})$ under irrigated lowland and aerobic conditions respectively. IR 36 recorded the highest mean value for maximum numbers of characters ( 5 each) in both the environments.

Table.1 List of fifteen parental genotypes evaluated for genetic parameters under irrigated lowland and aerobic condition

\begin{tabular}{|c|l|l|}
\hline Sl. No. & Genotype & Pedigree \\
\hline $\mathbf{1}$ & Nagina 22 & Selection from Rajbhog \\
\hline $\mathbf{2}$ & Inglongkiri & Pureline selection in landrace \\
\hline $\mathbf{3}$ & Aus Joria & Landrace \\
\hline $\mathbf{4}$ & Banglami & Pureline selection in landrace \\
\hline $\mathbf{5}$ & Kasalath & Pureline selection in landrace \\
\hline $\mathbf{6}$ & Dimrow & Landrace \\
\hline $\mathbf{7}$ & Tamdao & Introduction \\
\hline $\mathbf{8}$ & Koimurali & Landrace \\
\hline $\mathbf{9}$ & Guni & Landrace \\
\hline $\mathbf{1 0}$ & Dehangi & Pureline selection in landrace \\
\hline $\mathbf{1 1}$ & Luit & Heera/Annada \\
\hline $\mathbf{1 2}$ & IR 36 & IR 1561-228-1-2/IR1737//CR 94-13 \\
\hline $\mathbf{1 3}$ & Kmj 13A 6-1-2 & Mahsuri/Luit \\
\hline $\mathbf{1 4}$ & Gopinath & Pusa 2-21 x IR 36 \\
\hline $\mathbf{1 5}$ & Sahabhagi & IR 55419-04/Way Rarem \\
\hline
\end{tabular}


Table.2 Analysis of variance for fifteen rice genotypes in aerobic and irrigated lowland environments

\begin{tabular}{|c|c|c|c|c|c|c|c|c|c|c|c|c|c|c|c|c|c|c|}
\hline \multirow[t]{2}{*}{ Source } & \multirow[t]{2}{*}{ df } & \multicolumn{17}{|c|}{ Mean sum of squares } \\
\hline & & PH & HGR & PT & DA & DM & PHI & SF & GY & HI & HGW & RWC & $\mathbf{R W}$ & SW & RSR & RV & Pro. & Chl. \\
\hline & \multicolumn{18}{|c|}{ Environment: Aerobic } \\
\hline Replication & 2 & $94.32^{* *}$ & $0.0088^{*}$ & $24.31^{* *}$ & 4.69 & 8.27 & 0.009 & 5.33 & 17.55 & 0.001 & $0.048^{* *} 5$ & $50.82^{* *} 1$ & $17.00^{* *}$ & $46.40^{* *}$ & 0.001 & 12.66 & 10.29 & $0.147^{*}$ \\
\hline Genotype & 14 & $1261.10^{* *}$ & $0.2445^{* *}$ & $72.20^{* *}$ & $205.74^{* *}$ & $1093.90^{* *}$ & $0.048^{* *}$ & $332.24^{* *} 9$ & $98.82^{* *}$ & $0.041^{* *} \mathrm{C}$ & $0.217^{* *} 3$ & $325.32^{* *} 8$ & $87.38^{* *}$ & $608.27^{* *} 0$ & $0.015^{* *} 6$ & $685.65^{* *} 2$ & $2870.74^{* *}$ & $0.217^{* *}$ \\
\hline \multirow[t]{2}{*}{ Error } & 28 & 14.52 & 0.0025 & 2.270 & 5.62 & 7.22 & 0.005 & 8.18 & 5.33 & 0.003 & 0.008 & 1.79 & 2.20 & 6.13 & 0.001 & 17.33 & 28.55 & 0.037 \\
\hline & \multicolumn{18}{|c|}{ Environment: Irrigated lowland } \\
\hline Replication & 2 & 6.53 & 0.0008 & 3.02 & 4.62 & 0.29 & 0.001 & 0.37 & 1.03 & 0.0003 & \begin{tabular}{l|l}
3 & 0.081
\end{tabular} & 18.40 & 14.65 & 29.27 & 0.002 & 2.84 & 48.01 & 0.159 \\
\hline Genotype & 14 & $1151.61^{* *}$ & $0.2647^{* *}$ & $29.74^{* *}$ & $237.12^{* *}$ & $1032.88^{* *}$ & $0.012^{* *}$ & * $115.64^{* * *}$ & $62.71^{* *}$ & $0.039^{* *}$ & $0.276^{* *}$ & $77.35^{* *}$ & $68.45^{* *}$ & $683.61^{* *}$ & $0.010^{* *}$ & * $446.58^{* *}$ & * $631.12^{* *}$ & $0.370^{* * *}$ \\
\hline Error & 28 & 5.50 & 0.0013 & 2.97 & 5.62 & 6.74 & 0.003 & 21.02 & 6.96 & 0.003 & 0.034 & 9.34 & 8.63 & 23.04 & 0.002 & 17.21 & 78.95 & 0.060 \\
\hline
\end{tabular}

[DA- Days to anthesis; DM-Days to maturity; PT-Number of productive tillers; PH-Plant height; HGR-Height growth rate; PHI- Panicle harvest index; SFSpikelet fertility; GY-Grain yield per plant; HI- Harvest index; RWC- Relative water content; Pro.- Proline content; Chl.-Chlorophyll content; RW- Root weight; SW-Shoot weight; RSR- Root shoot ratio; RV- Root volume] 
Table.3 Pooled analysis of variance for fifteen parental rice genotypes under aerobic and irrigated lowland environments

\begin{tabular}{|c|c|c|c|c|c|c|c|c|c|c|c|c|c|c|c|c|c|c|}
\hline Sources & df & DA & DM & PH & HGR & ET & PHI & SF & HGW & GY & HI & RWC & PRO & CHL & $\mathbf{R W}$ & SW & RSR & RV \\
\hline $\begin{array}{l}\text { Replication } \\
\text { in } \\
\text { Environment }\end{array}$ & 4 & 4.66 & 4.28 & $50.4^{* *}$ & $0.005^{*}$ & $13.66^{* *}$ & 0.005 & 2.85 & $0.06^{* *}$ & 9.29 & 0.001 & $34.61^{* *}$ & 29.15 & $0.15^{* *}$ & $15.83^{* *}$ & $37.84^{* *}$ & 0.001 & 7.75 \\
\hline Environment & 1 & $352.04^{* *}$ & 401.1 & $639.7^{* *}$ & $0.194^{* *}$ & $23.77^{* *}$ & 0.00 & $148.18^{* *}$ & 0.003 & $184.49^{* *}$ & $0.233^{* *}$ & $359.3^{* *}$ & $1479.0^{* *}$ & $1.44^{* *}$ & $114.9^{* *}$ & $1573.8^{* *}$ & 0.001 & $361.4^{* *}$ \\
\hline Genotypes & 14 & $437.46^{* *}$ & $2118.6^{* *}$ & $2397.0^{* *}$ & $0.506^{* *}$ & $90.10^{* *}$ & $0.05^{* *}$ & $385.98^{* *}$ & $0.485^{* *}$ & $149.38^{* *}$ & $0.077^{* *}$ & $339.0^{* *}$ & $2961.6^{* *}$ & $0.52^{* *}$ & $137.8^{* *}$ & $1275.0^{* *}$ & $0.017^{* *}$ & $1097.5^{* *}$ \\
\hline Env. X Gen. & 14 & 5.45 & 8.18 & 15.7 & 0.003 & $11.84^{* *}$ & $0.01^{*}$ & $61.91^{* *}$ & 0.009 & $12.16^{*}$ & 0.003 & $63.8^{* *}$ & $540.3^{* *}$ & 0.07 & $18.0^{* *}$ & 16.44 & $0.008^{* *}$ & $34.8^{*}$ \\
\hline Pooled Error & 56 & 4.92 & 6.98 & 10.01 & 0.002 & 2.62 & 0.004 & 14.60 & 0.02 & 6.14 & 0.003 & 5.57 & 53.75 & 0.05 & 5.42 & 14.59 & 0.001 & 17.27 \\
\hline Total & 89 & 76.92 & 343.64 & 395.3 & 0.084 & 18.57 & 0.012 & 81.43 & 0.094 & 31.76 & 0.017 & 72.44 & 602.60 & 0.15 & 29.92 & 231.78 & 0.005 & 193.38 \\
\hline $\begin{array}{l}\text { General } \\
\text { Mean }\end{array}$ & & 73.00 & 110.42 & 118.1 & 1.104 & 15.34 & 0.797 & 80.29 & 2.04 & 20.72 & 0.39 & 85.30 & 53.41 & 1.36 & 16.05 & 57.28 & 0.269 & 34.62 \\
\hline C.V. & & 3.05 & 2.37 & 2.9 & 4.021 & 11.79 & 7.885 & 4.7 & 7.37 & 12.09 & 10.85 & 2.88 & 13.52 & 16.95 & 15.60 & 6.6 & 14.38 & 11.85 \\
\hline \multicolumn{19}{|l|}{ C.D. $95 \%$} \\
\hline $\begin{array}{l}\text { Bi.-Bj. } \\
\text { (GEN) }\end{array}$ & & 2.57 & 3.03 & 4.0 & 0.051 & 2.09 & 0.073 & 4.36 & 0.17 & 2.90 & 0.05 & 2.84 & 8.35 & 0.27 & 2.89 & 4.37 & 0.045 & 4.74 \\
\hline AiBi-AiBj & & 3.63 & 4.28 & 6.0 & 0.073 & 2.96 & 0.103 & 6.17 & 0.25 & 4.09 & 0.07 & 4.02 & 11.81 & 0.38 & 4.09 & 6.18 & 0.063 & 6.71 \\
\hline
\end{tabular}

$* \mathbf{p}<0.5 ; * * \mathbf{p}<0.01$

[DA- Days to anthesis; DM-Days to maturity; PT-Number of productive tillers; PH-Plant height; HGR-Height growth rate; PHI- Panicle harvest index; SFSpikelet fertility; GY-Grain yield per plant; HI- Harvest index; RWC- Relative water content; Pro.- Proline content; Chl.-Chlorophyll content; RW- Root weight; SW- Shoot weight; RSR- Root shoot ratio; RV- Root volume] 
Table.4 Mean performance, genotypic and phenotypic coefficients of variation of parents in aerobic and irrigated lowland environments

\begin{tabular}{|c|c|c|c|c|c|c|c|c|c|c|c|c|c|c|c|c|c|}
\hline Components & PH & HGR & PT & DA & DM & PHI & SF & GY & HI & HGW & RWC & RW & SW & RSR & $\mathbf{R V}$ & Pro. & Chl. \\
\hline \multicolumn{18}{|c|}{ Environment: Aerobic } \\
\hline Mean & 115.4 & 1.06 & 15.86 & 74.98 & 112.53 & 0.79 & 79.01 & 22.15 & 0.43 & 2.05 & 83.30 & 14.92 & 53.10 & 0.27 & 36.63 & 49.36 & 1.23 \\
\hline Max & 146.5 & 1.67 & 26.60 & 88.67 & 134.67 & 0.92 & 90.04 & 31.50 & 0.65 & 2.60 & 92.67 & 26.24 & 78.53 & 0.38 & 67.67 & 110.33 & 1.86 \\
\hline Min & 77.74 & 0.69 & 8.83 & 61.33 & 87.33 & 0.53 & 55.67 & 14.37 & 0.30 & 1.62 & 53.90 & 8.22 & 31.87 & 0.19 & 18.10 & 18.00 & 0.74 \\
\hline SE & 3.11 & 0.04 & 1.23 & 1.94 & 2.19 & 0.06 & 2.33 & 1.88 & 0.05 & 0.07 & 1.09 & 1.21 & 2.02 & 0.02 & 3.40 & 4.36 & 0.16 \\
\hline $\mathrm{CV}$ & 3.30 & 4.74 & 9.50 & 3.16 & 2.39 & 8.75 & 3.62 & 10.42 & 13.00 & 4.41 & 1.61 & 9.95 & 4.66 & 8.78 & 11.37 & 10.83 & 15.57 \\
\hline PCV & 17.96 & 27.26 & 31.90 & 11.34 & 17.08 & 17.55 & 13.64 & 27.28 & 29.10 & 13.63 & 12.57 & 37.07 & 27.08 & 26.68 & 42.31 & 63.30 & 25.25 \\
\hline GCV & 17.66 & 26.85 & 30.45 & 10.89 & 16.91 & 15.22 & 13.15 & 25.21 & 26.04 & 12.89 & 12.47 & 35.71 & 26.68 & 25.20 & 40.75 & 62.36 & 19.89 \\
\hline ECV & 3.30 & 4.74 & 9.50 & 3.16 & 2.39 & 8.75 & 3.62 & 10.42 & 13.00 & 4.41 & 1.61 & 9.95 & 4.66 & 8.78 & 11.37 & 10.83 & 15.57 \\
\hline Heritability & 96.62 & 96.97 & 91.12 & 92.23 & 98.05 & 75.18 & 92.96 & 85.40 & 80.03 & 89.52 & 98.37 & 92.80 & 97.04 & 89.17 & 92.78 & 97.07 & 62.01 \\
\hline $\operatorname{CD}(5 \%)$ & 6.37 & 0.08 & 2.52 & 3.96 & 4.49 & 0.12 & 4.78 & 3.86 & 0.09 & 0.15 & 2.24 & 2.48 & 4.14 & 0.04 & 6.96 & 8.93 & 0.32 \\
\hline $\begin{array}{c}\text { GA as \% of } \\
\text { mean }\end{array}$ & 35.76 & 54.46 & 59.88 & 21.55 & 34.50 & 27.18 & 26.13 & 47.99 & 47.98 & 25.13 & 25.47 & 70.87 & 54.14 & 49.01 & 80.86 & 126.58 & 32.26 \\
\hline \multicolumn{18}{|c|}{ Environment: Irrigated lowland } \\
\hline Mean & 120.8 & 1.15 & 14.83 & 71.02 & 108.31 & 0.81 & 81.58 & 19.28 & 0.33 & 2.04 & 87.29 & 17.18 & 61.47 & 0.27 & 32.62 & 57.46 & 1.48 \\
\hline Max & 150.1 & 1.75 & 21.67 & 85.33 & 128.33 & 0.89 & 89.50 & 28.20 & 0.60 & 2.70 & 93.67 & 28.97 & 86.73 & 0.35 & 58.20 & 88.58 & 2.17 \\
\hline Min & 85.30 & 0.75 & 10.39 & 58.67 & 81.00 & 0.69 & 70.05 & 13.30 & 0.21 & 1.50 & 76.67 & 8.43 & 34.37 & 0.15 & 15.29 & 36.81 & 0.88 \\
\hline $\mathbf{S E}$ & 1.91 & 0.03 & 1.41 & 1.68 & 2.12 & 0.05 & 3.74 & 2.15 & 0.05 & 0.15 & 2.50 & 2.40 & 3.92 & 0.04 & 3.39 & 7.25 & 0.20 \\
\hline $\mathrm{CV}$ & 1.94 & 3.10 & 11.62 & 2.89 & 2.40 & 6.95 & 5.62 & 13.68 & 16.70 & 9.05 & 3.50 & 17.10 & 7.81 & 18.14 & 12.72 & 15.46 & 16.45 \\
\hline PCV & 16.30 & 25.95 & 23.26 & 12.74 & 17.24 & 9.56 & 8.89 & 26.21 & 36.79 & 16.63 & 6.48 & 31.12 & 25.37 & 26.20 & 38.82 & 28.22 & 27.19 \\
\hline GCV & 16.18 & 25.76 & 20.14 & 12.41 & 17.08 & 6.57 & 6.88 & 22.36 & 32.78 & 13.96 & 5.45 & 25.99 & 24.14 & 18.90 & 36.68 & 23.61 & 21.66 \\
\hline ECV & 1.94 & 3.10 & 11.62 & 2.89 & 2.40 & 6.95 & 5.62 & 13.68 & 16.70 & 9.05 & 3.50 & 17.10 & 7.81 & 18.14 & 12.72 & 15.46 & 16.45 \\
\hline Heritability & 98.58 & 98.57 & 75.03 & 94.85 & 98.07 & 47.19 & 60.01 & 72.76 & 79.39 & 70.41 & 70.81 & 69.78 & 90.53 & 52.04 & 89.27 & 69.98 & 63.41 \\
\hline $\operatorname{CD}(5 \%)$ & 3.92 & 0.06 & 2.88 & 3.43 & 4.34 & 0.09 & 7.67 & 4.41 & 0.09 & 0.31 & 5.11 & 4.91 & 8.03 & 0.08 & 6.94 & 14.86 & 0.41 \\
\hline $\begin{array}{c}\text { GA as } \% \text { of } \\
\text { mean }\end{array}$ & 33.10 & 52.68 & 35.95 & 24.89 & 34.83 & 9.30 & 10.99 & 39.28 & 60.17 & 24.13 & 9.45 & 44.73 & 47.32 & 28.09 & 71.38 & 40.69 & 35.52 \\
\hline
\end{tabular}


The mean sums of squares were subjected to estimation of genetic parameters (Table 4). The highest genotypic coefficient of variation $(\mathrm{GCV})$ and phenotypic coefficient of variation (PCV) were observed for proline content $(62.4,63.3)$ followed by root volume (40.8, 42.3) and root weight (35.8, $37.1)$ in aerobic condition. However, under irrigated lowland condition root volume exhibited the highest GCA (36.7) and PCV (38.8) followed by root weight $(26.0,31.1)$ and height growth rate $(25.8,26.0)$. Heritability estimate was found to be the highest for relative water content (98.4), followed by days to maturity (98.1) and proline content (97.1) under aerobic condition. Heritability gives the information on the magnitude of inheritance of quantitative traits. Heritability value alone may be misleading during selection. Therefore, heritability and genetic advance together should be taken into consideration for selection (Johnson et al., 1955). Under aerobic condition proline content, height growth rate, shoot weight, grain yield and plant height exhibited high heritability with high genetic advance as percent of mean. Findings corroborated with the report of Vanitha et al., (2015) in aerobic rice.

Under irrigated lowland condition plant height exhibited the highest heritability (98.6) followed by height growth rate (98.6) and days to maturity (98.1). High estimates of heritability with relatively higher genetic advance were recorded for harvest index, root volume, shoot weight, days to maturity, height growth rate and plant height under irrigated lowland. Sathya (2014) and Karpagam et al., (2014) also reported similar findings in rice. Sarma et al., (2015) reported more than $90 \%$ heritability in indigenous rice germplasm of Assam under aerobic condition.

Higher PCV value over corresponding GCV for all the characters indicated that environment plays an important role in the expression of these characters. Vanitha et al., (2015) also reported similarly in aerobic rice. The difference between corresponding PCV and GCV gives an idea about the intensity of environmental variation on expression of the character. Higher estimates of this difference for chlorophyll content, harvest index, panicle harvest index and grain yield, root weight, root shoot ratio suggested the importance of environment on expression of the characters. Proline content, 100 grain weight and number of productive tillers when grown in aerobic condition were highly influenced by environment but less influenced under irrigated lowland condition. Ramanjaneyulu et al., (2014) also reported similar findings for various traits in rice. Corresponding heritability and genetic advance estimates under respective environments also supported the same.

Overall, the magnitude of PCV and GCV for most of the characters were observed to be higher under aerobic condition whereas, magnitude of difference between PCV and GCV were high under irrigated lowland condition than the aerobic condition. Sathya and Jebaraj (2015) also reported lower difference between PCV and GCV in aerobic rice. Findings corroborated with Sathya (2014) and Karpagam et al., (2014). Similarly, higher estimate of heritability and GA for most of the characters were observed under aerobic condition. These findings suggested greater role of environment in expression of the characters under irrigated condition. Lesser environmental influence in aerobic condition allows the genotypes to be used reliably predicting phenotypes.

Presence of sufficient variability in the characters studied offered possibilities to explore the material for further genetic improvement. Lower influence of environmental variation in aerobic condition in the present investigation could be quite 
helpful in exploiting the genetic variation for yield attributing and adaptive traits in aerobic rice breeding programe. Proline content, height growth rate, shoot weight, grain yield and plant height exhibited high heritability with high genetic advance as percent of mean hence, these characters showed promise in bringing genetic improvement under selection in aerobic condition.

\section{References}

Atlin, G.N., Lafitte; Tao, H.R., Laza, D., Amante, M. and Courtois, B. (2006). Developing rice cultivars for highfertility upland systems in the Asian tropics. Field Crops Res. 97: 43-52.

Johnson, H.W., Robinson, H.F. and Comstock, R.E. 1955. Estimation of genteic and environmental variability in soyabean (Glycine max (L.) Merril.). Agron. J. 47 (4): 314-318.

Karpagam, V., Jebaraj, S., Rajeswari, S., Vanniarajan, C., Balakrishnan, K. and Muthamilan, M. 2014. Genetic Studies of Root and Yield Traits for Drought Tolerance in Rice (Oryza sativa. L). Trends Biosci. 7 (15): 2004-2006.

Nilanjaya; Kumar, C. and Narayan, A. 2015. Genetic Variability for Yield and Related Attributes in Aerobic Rice (Oryza sativa L.). Trends in Biosci. 8 (8): 1935-1937.
Patel, S.K. (2015). Genetic analysis of yield and its components traits in rice (Oryza sativa L.). Electron J. Plant Breed. 6 (1): 19-25.

Ramanjaneyulu, A.V., Gourishankar,V., Neelima, T.L. and Shashibhusahn, D. 2014. Genetic analysis of rice (Oryza sativa L.) Genotypes under aerobic Conditions on alfisols. SABRAO J. Breed. Genet. 46 (1): 99-111.

Sarma, M.K., Goswami, R.K., Sharma, A.K., Baruah, M., Sarma, D. and Neog, P. 2015. Genetic variability and diversity in indigenous rice Germplasm of Assam under aerobic condition. Prog. Agric. 15 (1): 66-70.

Sathya, R. 2014. Genetic Studies (Heritability and Genetic Advance) from Three Line Rice Hybrids under Aerobic Condition. Trends in Biosci. 7 (18): 2642-2645.

Sathya, R. and Jebaraj, S. 2015. Evaluation of aerobic hybrid analysis of combining ability in three line hybrids in Rice (Oryza sativa 1.) under aerobic conditions. Afr. J. Agric. Res. 10 (18): 1971-1981

Vanitha, J., Usha Kumari, R., Amudha, K. and Robin, S. 2015. Genetic evaluation of rice genotypes for zinc deficiency tolerance and yield traits under aerobic condition in rice. Electron J. Plant Breed. 6 (1): 191195.

\section{How to cite this article:}

Hrishikesh Ojah, P. Talukdar, D. Sarma and Rumjhum Goswami. 2019. Genetic Variability for Yield and Yield Contributing Traits of Rice under Aerobic Condition in Assam, India. Int.J.Curr.Microbiol.App.Sci. 8(07): 1530-1537. doi: https://doi.org/10.20546/ijcmas.2019.807.182 